\title{
Causes, management and complications of ascites: a review
}

\author{
*Hirra Tasneem, Huda Shahbaz and Bushra Ali Sherazi \\ Institute of Pharmacy, Lahore College For Women University, Jail Road Lahore, 54000, Pakistan
}

\begin{abstract}
Ascites is the pathological state in which fluid accumulates in the peritoneal cavity. Fluid accumulation may be due to infection and malignancy or due to other diseases like liver disease, heart failure, and renal disease. The ascitic fluid can be graded into Transudative and Exudative fluid based on the serum ascites albumin gradient (SAAG). The prominent cause of ascites is found to be Liver Cirrhosis. The most common symptom of Ascites is recent weight gain, increased abdominal girth and dyspnea. The first line treatment of ascites includes education regarding dietary sodium restriction and oral diuretics. However, other mechanical methods can also be used if the patient is unresponsive to this approach. But, there are some limitations while using these mechanical methods. Ascites is also associated with certain complications like spontaneous bacterial perotinitis, hepatorenal syndrome and dilutional hyponatremia. Ascites itself is not fatal unless it becomes infected. So, early diagnosis and effective treatment should be ensured in order to avoid further complications. This review focuses on the grades, causes, symptoms, management and complications of Ascites.
\end{abstract}

Key Words: SAAG, causes, cirrhosis, management, diuretics, paracentesis.

\section{INTRODUCTION}

Ascites is derived from a Greek term "ASKOS" which refers to a bag or sac. It is the pathological accumulation of free fluid in the peritoneal cavity. The fluid accumulates because of conditions directly involving the peritoneum (infection, malignancy), or due to other diseases remote from the peritoneum (i.e., liver disease, heart failure, hypoproteinaemia). Normally there is no fluid in the peritoneal cavity, however in women a small amount (almost $20 \mathrm{ml}$ ) or less than 1 ounce can sometimes (but not often) can be present depending on her menstrual cycle (Ascites-1), but for the confirmation of ascites, it is required that at least $1500 \mathrm{ml}$ of fluid should be present in peritoneal cavity and also detectable by clinical examination but significantly more in obese person (ascites-2) (Muhammed et al., 2012; $\mathrm{Al}$ Knawy, 1997).

\section{GRADING OF ASCITES}

Ascites exists in three grades namely, grade 1 which is mild, only visible on ultrasound and CT scan, grade 2 which is determined with flank bulging and shifting dullness and grade 3 is directly visible, and is confirmed with the fluid wave/thrill test. Traditionally, ascites was divided into 2 types, transudative and exudative type. This classification was based on the amount of protein found in the fluid. A more meaningful system has been developed, on the basis of amount of albumin in the ascitic fluid in contrast to serum albumin (albumin measured in the blood). This system is called the Serum Ascites Albumin Gradient or SAAG. Ascites due to portal hypertension caused cirrhosis, congestive heart failure or Budd-Chiari has SAAG value generally greater than 1.1. Ascites related to other reasons (malignancy, pancreatitis) has value lower than 1.1. Another grading system adapted from European Association for the study of the liver is given in table 1 (Moore \& Wong, 2003).

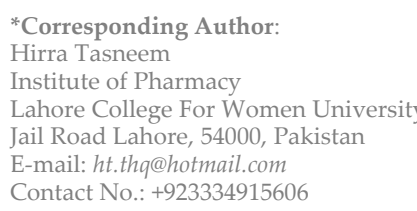

\section{PATHOPHYSIOLOGY \& CAUSES OF ASCITES}

Ascites generally results from portal hypertension and low levels of a protein called albumin. Diseases that can lead to severe liver damage can cause ascites. These diseases include long-term hepatitis C or B infection and alcohol abuse over many years. People suffering from certain cancers in the abdomen may develop ascites. These cancers include colon, ovaries, uterus, pancreas, and liver cancer. Other conditions that can lead to this problem include, clots in the veins of the liver (portal vein thrombosis), congestive heart failure, pancreatitis, thickening and discoloring of the sac like covering of the heart. Kidney dialysis may also be linked with ascites (Runyon, 2009). Table 2 depicts some of the common causes of ascites.

\section{Ascites due to liver cirrhosis}

Literature showed that Cirrhosis is the commonest cause of ascites in the Western world $(\sim 75 \%)$, followed by peritoneal malignancy $(12 \%)$, cardiac failure $(5 \%)$ and peritoneal tuberculosis (2\%) (Runyon, 1993).

\section{Mechanism of ascites in cirrhosis}

The mechanism of ascites in cirrhosis is complex but portal hypertension and renal sodium retention is common. The history shows that cirrhotic ascites progresses from diuretic responsive (uncomplicated) ascites to the development of dilutional hyponatraemia, refractory ascites, and finally, hepatorenal syndrome (HRS). While survival of patients who develop ascites in 1 year is $85 \%$, it declines to $25 \%$ once it has progressed to hyponatraemia, refractory ascites or HRS (Planas et al., 2004).

In considering portal hypertension, backflow and stasis of vasodilatory substances, e.g., nitric oxide, begin to aggregate. This causes, amongst other results visceral vasodilation with resultant hypoperfusion of the renal system. Thus by this way renin angiotensin- aldosterone system (RAAS) is activated leading to aggressive fluid retention. In short, renin is secreted from the renal juxtaglomerular apparatus (JGA) around the proximal nephrons in reaction to changes in vascular pressures, changes in serum sodium, and from activation of the 
Table 1: Grading of ascites (Fullwood \& Purushothaman, 2014).

\begin{tabular}{cll}
\hline Grade & Detection Technique & Abdominal Distension \\
\hline $\mathbf{1}$ & Ultrasound & $\begin{array}{l}\text { Absent }(<500 \mathrm{ml} \text { of fluid }) \\
\text { Moderately distended }\end{array}$ \\
$\mathbf{2}$ & $\begin{array}{l}\text { anspection, palpation } \\
\text { Inspection, palpation } \\
\text { and percussion }\end{array}$ & $\begin{array}{l}\text { Grossly or markedly } \\
\text { distended }\end{array}$ \\
\hline
\end{tabular}

sympathetic nervous system. In turn, it will change angiotensinogen (made in the liver) to angiotensin-I which is further converted to angiotensin-II by angiotensin converting enzyme (ACE) in the lungs. Angiotensi-II has various important functions that drive fluid accession and retention, including stimulation of the thirst drive, release of aldosterone from the zona glomerulosa of the adrenal cortex, and the secretion of vasopressin from the posterior pituitary. Pathophysiology of ascites is clearly shown in figure 1 (Teirstein et al., 2005; Garcia-Tsao, 2011; Henriksen and Møller, 2005; Llach et al., 1988).

The development of ascites, in cirrhotic patients, marks the transition from compensated to decompensated cirrhosis Accumulation of ascitic fluid in cirrhosis results from different factors broadly defined in terms of cytokine and hormonal dysregulation and associated volume overload in the context of portal hypertension (Ginés et al., 1987).

The presence of ascites leads to the progression of cirrhosis. It is also the most common cause for hospital admissions and thus increases unpredicted cost; it increases 1-year mortality and functions as a risk for orthotopic liver transplantation (OLT). In portal hypertension, the major cause of ascites is Cirrhosis (85\%). Other causes of ascites (non-cirrhotic) can be widely defined as pre- or post-hepatic in origin (Moore and Thiel, 2013).

\section{Extra-hepatic causes of ascites}

Although cirrhosis is the main cause of ascites in majority of the patients, however almost $15 \%$ have a cause other than liver disease, which can be cancer, cardiac failure, nephrotic syndrome or tuberculosis. Approximately 5\% of patients with ascites have mixed ascites demonstrated by 2 or more underlying causes of ascites formation. Such patients have cirrhosis plus 1 other cause i.e., peritoneal carcinomatosis or peritoneal tuberculosis. Many patients with inexplicable ascites are finally found to have 2 or even 3 causes for ascites formation (e.g., heart failure, diabetic nephropathy, and cirrhosis due to non-alcoholic steatohepatitis). In this setting, the aggregate of predisposing factors can lead to sodium and water retention when every individual factor might not be severe enough to cause surplus fluid (Runyon et al., 1992).

Ascites may be due to multiple reasons other than the liver diseases or portal hypertension, thus can be ruled out by the laboratory testing and imaging. As in case of chronic pancreatitis with associated pseudocyst and internal fistulae formation, major fluid can directly enter into the peritoneal cavity and appearing as abdominal distention with pain. In general, raised ascitic fluid amylase level, found on diagnostic paracentesis, is a firm diagnostic for this category. The physician might be troubled with the diagnosis in a patient with a compelling history of steatorrhea, alcohol use and chronic pancreatitis. Particularly, the serum-ascites albumin gradient (SAAG) is a helpful tool for differentiating ascites-associated disease processes caused by portal hypertension (e.g. cirrhosis), from the many other nonportal hypertensive
Table 2: Possible causes of ascites (Marthadu, 2014).

\begin{tabular}{|c|c|}
\hline Source & Cause \\
\hline \multirow[t]{4}{*}{ Hepatic Source } & Cirrhosis \\
\hline & Alcoholic Hepatitis \\
\hline & Budd-Chiari Syndrome \\
\hline & Sinusoidal Obstruction Syndrome \\
\hline \multirow{5}{*}{$\begin{array}{l}\text { Extra-Hepatic } \\
\text { Source }\end{array}$} & Heart Failure \\
\hline & Nephrotic Syndrome \\
\hline & Pancreatitis \\
\hline & Myxedema \\
\hline & $\begin{array}{l}\text { Cancer related (peritoneal metastases, } \\
\text { massive liver metastases, etc.) }\end{array}$ \\
\hline Mixed Source & $\begin{array}{l}\text { Ascites that results from combination of } 2 \text { or } \\
\text { more causes }\end{array}$ \\
\hline
\end{tabular}

causes of ascites. A SAAG value $\geq 1.1 \mathrm{~g} / \mathrm{dL}$ strongly reinforce ( $97 \%$ sensitivity) in the diagnosis of portal hypertension as a cause (Becker et al., 2006).

\section{Malignant Ascites}

Malignant ascites, which is found in $10 \%$ of cases, is commonly because of peritoneal metastasis in neoplastic disease, but it is more common with ovary, breast, gastric, pancreatic, bronchus or colon cancer. Almost in 20\% of cases with malignant ascites tumor is of unknown origin and mostly protein content is high in malignant ascites (Becker et al., 2006).

\section{Pathogenesis of Ascites}

Besides its well-known demonstration, the pathogenesis of ascites remains unclear and continues to evolve. A hybrid theory currently predominates, which up rise from the "overflow" and "underfill" theories of the past generation. A brief adumbrate of these views suggests that the continuous injury to the liver as a combination of both exogenous factors, like viral or non-alcoholic steatohepatitis (NASH) or chronic alcohol injury; in the setting of an appropriate genetic disposition; and continued micro-processes of inflammation, collagen deposition/regeneration and necrosis, all conspiring to transubstantiate the liver from a low-resistance to a highresistance system, like a spectrum of fibrosis with vascular smooth muscle dysfunction. These collective processes can lead to increased pressure in the portal vein, leading to portal hypertension (Moore and Thiel, 2013). Sequence of events for the hypothesis of ascites formation can be seen in table 3.

Usually, in rest condition when the peritoneal cavity is relaxed, it has a pressure of about $5-10 \mathrm{mmHg}$, which has almost $25-50 \mathrm{~mL}$ of serous fluid. The serous fluid normally provides a low resistance film over which bowel can move past each other and further hydrates the serosal surfaces maintaining suppleness and haleness. The maximal absorption of fluid out of the peritoneum is approximately $850 \mathrm{~mL} / \mathrm{d}$ in the most effective circumstances. Peritoneal dialysis works under the theory of selective filteration, and it can be observed effective filtration is altered by modifications in the properties of

Table 3: Sequence of events for the hypothesis of ascites formation (Garcia-Tsao, 2011).

\begin{tabular}{ccc}
\hline Event & $\begin{array}{c}\text { Underfill/peripheral arterial } \\
\text { vasodilatation theory }\end{array}$ & $\begin{array}{c}\text { Overfill } \\
\text { theory }\end{array}$ \\
\hline Primary event & Vascular & Renal \\
Secondary event & Renal & Vascular \\
\hline
\end{tabular}




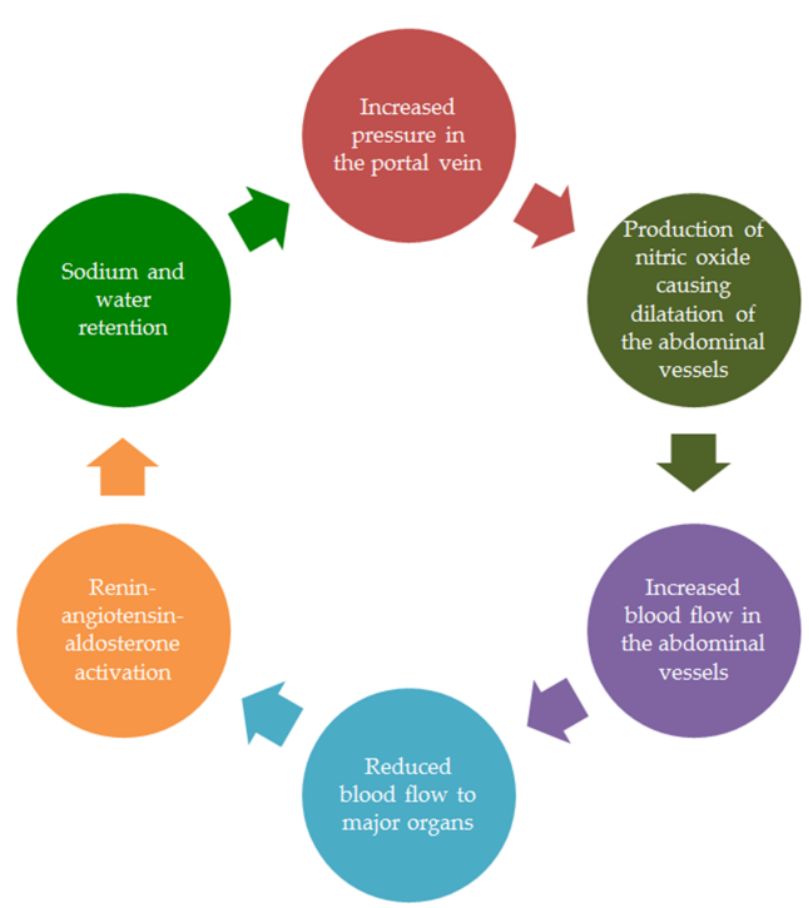

Figure 1: Pathophysiology of ascites (Fullwood and Purushothaman, 2014).

the peritoneal surface area or lymphatic system, either due to fibrotic or infectious, or by some inflammation or mechanical processes. Hence, continued impairment of physiological system can lead to profound ascitic fluid retention (Moore and Thiel, 2013).

\section{DETECTION OF ASCITES}

Identification of mild ascites is difficult, but abdominal distension is the clear indication of severe ascites. Patients suffering from ascites generally complaints about pressure and abdominal heaviness, as well as shortness of breath, because of the diaphragm mechanical impingement occur. Physical examination of the abdomen is a useful parameter for determining ascites, as there is visible "flank bulging" and "shifting dullness" in the reclining patient, or "fluid wave" or "fluid thrill" in the massive ascites (Runyon, 2009). Assessment of shifting dullness is also shown in figure 2 .

The appearance of a full, bulging abdomen should lead to percussion of the flanks. One should test for "shifting", if the amount of flank dullness is higher than usual. Around 1,500 mL of fluid must be present before flank dullness is detected. The patient has less chance of having ascites $(10 \%)$, if flank dullness is not detected. The fluid wave and puddle sign are not helpful. Ascites due to alcoholic cardiomyopathy can replicate that due to alcoholic cirrhosis. Jugular venous distension is shown in the former but not in the latter. The physical examination for detecting ascites in the obese patient is difficult. An abdominal ultrasound may be needed to determine with surety if fluid is present (Cattau et al., 1982).

Fluid due to portal hypertension can be promptly differentiated from fluid due to other causes. Also, in view of the high incidence of ascitic fluid infection at the time of admission to the hospital, an admission vigilance tap may detect unpredictable infection (Runyon et al., 1992; Pinzello et al., 1983).

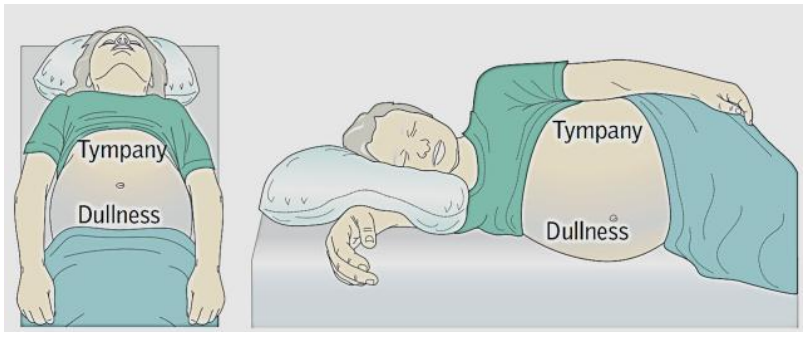

Figure 2: Assessment of shifting dullness (Fullwood and Purushothaman, 2014).

\section{SIGNS AND SYMPTOMS OF ASCITES}

The most prevalent symptoms are increased abdominal girth (the patient notices tightness of the belt or garments around the waist) and latter weight gain. As fluid continues to amass, it leads to elevation of the diaphragm that result in shortness of breath. Fluid aggregation may also be related with a feeling of satiety and generalized abdominal pain. Ascites can be distinguished from obesity, as the onset of symptoms in ascites is fast, while obesity develops from a period of months to years (Simel et al., 1988).

Depending on the underlying etiology, other signs and symptoms may also be present. For example, patients having ascites as a result of portal hypertension (may be due to fibrosis or cirrhosis of liver) may complain of gynecomastia, hematemesis, leg swelling, bruising or due to encephalopathy mental changes can also occur. Patients complaint of weight loss or chronic fatigue, when the cause of ascites is cancer (peritoneal carcinomatosis). Heart failure may also be a cause of ascites causing exercise intolerance, shortness of breath and wheezing in patients (Warrell et al., 2003).

\section{DIAGNOSIS OF ASCITES}

Tests of liver enzymes, coagulation, basic metabolic profile and routine complete blood count (CBC) should be performed for the diagnosis of ascites. Most of the experts suggest that if the ascites is newly developed or if the patient is hospitalized, then paracentesis should be performed as a diagnostic tool. The fluid is then analyzed for its gross appearance, albumin, protein level, and cell counts (red and white) (Warrell et al., 2003).

On the basis of physical examination and history, the assumption is made on the diagnosis of newly onset ascites. Ultrasound and successful abdominal paracentesis then confirms this diagnosis. Physical examination, past record and ascitic fluid analysis determines the cause of ascites formation. Generally, some other tests may also be needed. Moreover, the liver is routinely imaged commonly with ultrasound to in order to make diagnosis for hepatocellular carcinoma, portal vein thrombosis and hepatic vein thrombosis. The most economical and speedy method for diagnosis of etiology of ascites is abdominal paracentesis with adequate ascitic fluid examination (Runyon, 1994; Runyon et al., 2002).

Various Turkish, South African and local studies divulge that the major co-morbid of ascitic patients were fever, abdominal pain, night sweats, weight loss, abdominal swelling, clubbing and palmer erythema (Muhammed et al., 2012) 
Table 4: Treatment options for patients with ascites and cirrhosis (Runyon, 2009).

\begin{tabular}{llc}
\hline First Line & Second Line & Third Line \\
\hline Cessation of alcohol use, when present & $>$ Discontinue beta blockers, angiotensin converting $>$ Peritoneovenous shunt \\
$>$ Sodium restricted diet and diet education & enzyme inhibitors and angiotensin receptor \\
$>$ Dual dluretics, usually spironolactone and & blockers \\
furosemide, orally with single daily dosing & $>$ Consider adding midodrine especially in the \\
$>$ Discontinue non-steroidal anti-inflammatory & profoundly hypotensive patient \\
drugs & $>$ Serial therapeutic paracentesis \\
$>$ Evaluation for liver transplatation & $>$ Evaluation for liver transplantation \\
& $>$ Transjuglar intrahepatic portosystemic stent- \\
& shunt (TIPS) \\
\hline
\end{tabular}

\section{MANAGEMENT OF ASCITES}

Ascites is generally treated while an underlying cause is known, in order to prevent complications, relieve symptoms, and prevent further advancement. In those patients having mild ascites, therapy is usually given as an outpatient. The major aim of the therapy should be weight loss of not higher than $1.0 \mathrm{~kg} /$ day for patients having both ascites and peripheral edema and not greater than $0.5 \mathrm{~kg} /$ day for patients having ascites alone. In patients with severe ascites causing a tense abdomen, hospital admission is generally imperative for paracentesis (Ginès et al., 1987). Treatment options for patients with cirrhosis and ascites are depicted in table 4.

\section{First-line treatment}

The basic treatment guideline for the patients with ascites and cirrhosis is education with respect to dietary sodium (which should not be more than $2000 \mathrm{mg}$ per day [88 mmol per day]) and oral diuretics. When alacrity of weight loss is less than desired, urinary sodium excretion measurement is a useful parameter to follow (Runyon, 1994; Runyon et al., 2002).

Ascites can be speedily mobilized with severe sodium restriction, but it is not suggested as it is less palatable and may further worsen the malnutrition that is usually present in these patients as weight change and fluid loss are directly linked with the balance of sodium in patients with ascites caused by portal hypertension. Sodium restriction is responsible for weight loss, not fluid restriction, as sodium is followed by fluid passively. Random specimens are less informative in determining the rate of sodium excretion, as compared to twenty-fourhour collections of urine; however, full-day collections are cumbersome. Men suffering from cirrhosis should excrete creatinine not less than $15 \mathrm{mg} / \mathrm{kg}$ of body weight per day, and women should excrete not less than $10 \mathrm{mg} / \mathrm{kg}$ per day. Less creatinine indicates insufficient collection. In afebrile patients with cirrhosis without diarrhea, the overall sodium excretion (non-urinary) is less than 10 mmol per day. One of the aims of treatment is to enhance excretion of sodium in urine; so that it exceeds $78 \mathrm{mmol}$ per day (if intake is $88 \mathrm{mmol}$ per day then non-urinary excretion should be $10 \mathrm{mmol}$ per day). Only $10 \%$ to $15 \%$ of patients who are suffering from spontaneous natriuresis exceeding $78 \mathrm{mmol}$ per day can be acknowledged for sodium restriction in diet alone (i.e., without diuretics) (Garg et al., 2011; Eisenmenger et al., 1949).

Fluid restriction is not necessary in treating most patients with ascites and cirrhosis. The chronic hyponatremia usually present in cirrhotic ascites patients is sometimes morbid unless it is immediately corrected at the time of liver transplantation in the operating room. A study of 997 patients with ascites and cirrhosis showed that the sodium level in serum is not greater than 120 $\mathrm{mmol} / \mathrm{L}$ in only $1.2 \%$ of patients and not higher than 125 $\mathrm{mmol} / \mathrm{L}$ in only $5.7 \%$. In this setting, a try to rapidly correct hyponatremia with hypertonic saline can cause severe complications as compared to hyponatremia itself (Eisenmenger et al., 1950; Abbasoglu et al., 1998).

\section{Salt restriction}

The initial treatments in high SAAG ("transudate") are Salt restriction, which allows diuresis (production of urine) as the patient now has more fluid than salt concentration. Salt restriction is fruitful in about $15 \%$ of patients (Gatta et al., 1991).

\section{Use of diuretics}

As dietary salt restriction is the basic approach in the treatment, and aldosterone is the hormone that tends to increase salt retention, so a medicine that counterbalances aldosterone should be used. Spironolactone is the drug of choice as it blocks the aldosterone receptor in the collecting tubule. This choice has been affirmed in a randomized controlled trial. Dose of diuretics for ascites should be once daily (Fogel et al., 1981).

Diuretic Regimen: Oral Spironolactone and furosemide are given as a single morning doses in the normal diuretic regimen, starting with $100 \mathrm{mg}$ of the spironolactone and $40 \mathrm{mg}$ of furosemide. Formerly, single-agent spironolactone was recommended, but hyperkalemia and the long half-life of spironolactone have limited its use as a single agent only in patients with minimal fluid overload. In a randomized control trial the use of furosemide as a single agent has been demonstrated to be less efficacious than spironolactone. Another randomized trial showed that only spironolactone should be used, while furosemide can be added only when patients are refractory. The time to mobilization of moderate ascites is shortened when initial treatment is given in combination, as demonstrated in another randomized trial. However another randomized trial indicates that initial combination treatment shortens the time to mobilization of moderate ascites. Most patients need combination treatment eventually. A study was performed which is said to be the largest involving a total of 3860 patients with both ascites and cirrhosis, in which combination therapy was given from the beginning. For maintaining normokalemia and achieving rapid natriuresis, the preferred approach was to initiate the therapy with both drugs. Amiloride (10-40 mg per day) can be used in place of spironolactone in patients with tender gynecomastia. Nonetheless, amiloride is more expensive and has been shown to be less effective than an active metabolite of spironolactone in a randomized controlled trial. For the treatment of ascites metolazone, triamterene and hydrochlorothiazide have also been used. While using the combination of spironolactone and furosemide, 
Table 5: Complications, symptoms and proposed treatment of ascites (Fullwood and Purushothaman, 2014).

\begin{tabular}{lll}
\hline Complications & Symptoms & Treatments \\
$\begin{array}{l}\text { Spontaneous } \\
\text { bacterial peritonitis }\end{array}$ & Abdominal pain, fever. May be asymptomatic. & $\begin{array}{l}\text { Antibiotic administration. Large volume paracentesis } \\
\text { should be withheld until infection is treated effectively. }\end{array}$ \\
$\begin{array}{l}\text { Dilutional } \\
\text { hyponatraemia }\end{array}$ & $\begin{array}{l}\text { Increased peripheral oedema and re-accumulation of } \\
\text { ascites. }\end{array}$ & $\begin{array}{l}\text { Fluid restriction may be instigated if sodium is } \\
<130 \text { mmol/L, but should be used with caution }\end{array}$ \\
$\begin{array}{l}\text { Hepatorenal } \\
\text { Syndrome }\end{array}$ & $\begin{array}{l}\text { Reduced renal function, raised creatnine in the absence } \\
\text { of infection, shock or use of nephrotoxic drugs. }\end{array}$ & $\begin{array}{l}\text { Administration of the vasoconstrictor terlipressin in } \\
\text { combination with albumin. Liver transplantation. }\end{array}$ \\
\hline $\begin{array}{l}\text { Pleural effusion } \\
\text { Shortness of breath increased respiratory rate, reduced } \\
\text { air entry. }\end{array}$ & $\begin{array}{l}\text { Chest drains are contraindicated for this cause of pleural } \\
\text { effusion. First-line treatment includes diuretic administra- } \\
\text { tion and reduced sodium diet. }\end{array}$ \\
\hline
\end{tabular}

hyponatremia can rapidly develop if hydrochlorothiazide is added; so it should either be avoided or used with extreme caution. In the largest, multicenter, randomized controlled trial performed in patients suffering from ascites, dietary sodium restriction and a dual diuretic regimen with spironolactone and furosemide has been shown to be useful in more than $90 \%$ of patients in accomplishing a reduction in the volume of ascites to satisfactory levels (Angeloni et al., 2003).

Diuretics and albumin: A non-blinded randomized controlled trial in patients suffering from new onset ascites showed that $25 \mathrm{~g}$ infusions of albumin weekly, if given for 1 year preceded by infusions every 2 weeks enhanced survival related to diuretics alone (Wong et al., 2012).

\section{Treatment based on the cause of Ascites}

Treatment of ascitic patients depends on the cause of fluid accumulation. The SAAG can be helpful in identifying as well as in ruling regarding treatment. Patients with low SAAG $(<1.1 \mathrm{~g} / \mathrm{dL})$ ascites normally do not have portal hypertension and, with the omission of nephrotic syndrome, that do not answer to salt restriction and diuretics. In contrast, patients with a higher SAAG $(>1.1$ $\mathrm{g} / \mathrm{dL}$ ) have portal hypertension and usually are amenable to these measures. Liver injury due to alcohol intake is one of the most volatile causes of liver disease that leads to high SAAG ascites. Stopping alcohol intake is one of the useful steps to treat the underlying cause in this clinical setting. With self-restraint and time ascites may become more responsive to medical therapy (Runyon, 2002; Angeloni et al., 2003).

\section{Mechanical Methods}

If a patient is resistance to or shows poor response to diuretic therapy, then ultrafiltration or aquapheresis may be needed to achieve adequate control of fluid retention and congestion. The adoption of aforesaid mechanical methods of fluid removal can produce significant clinical benefits in patients with diuretic resistance and may restore responsiveness to conventional doses of diuretics. Water restriction may be needed if hyponatremia $(<130 \mathrm{mmol}$ per liter) develops (Hunt et al., 2005; Ginès et al., 2004).

\section{Therapeutic Paracentesis}

In patients having severe (tense) ascites, therapeutic paracentesis may be required. Albumin may sometimes be given intravenously in the amount equal to the proportion of ascites removed, as this method may decline serum albumin levels in blood (Salerno et al., 1987).

Site for Paracentesis: In the past, the midline was usually selected as the site for paracentesis. Nonetheless, the abdominal wall in the left lower fourth (quadrant), 2 fingerbreadths cephalad and 2 fingerbreadths medial to the anterior superior iliac spine, which has been delineated to be narrow and with a greater pool of fluid as compare to the midline. If the fluid is not easy to localize by examination because of obesity, ultrasonography can be helpful (Sakai et al., 2002).

Complications of Mechanical Methods: Even though older published series indicated a relatively high disease rate, and even death rate, when trocars were used for paracentesis, while in the recent studies no deaths or infections caused by paracentesis has been documented as the complication of paracenetsis in patients with ascites. Although $71 \%$ of the patients show abnormal prothrombin time, however, in only $1 \%$ of the patients, complications were detected. Although more serious complications (hemoperitoneum or bowel entry by the paracentesis needle) occur, they are sufficiently bizarre $(<1 / 1,000$ paracenteses) that they should not monish performance of this procedure. It is the common practice of some physicians to administer routinely blood products to cirrhotic patients with coagulopathy before performing paracentesis. This practice is not evidencesupported. The costs and risks of preventative transfusions surpass the benefit (Runyon, 1986; Webster et al., 1996).

Contraindications for performing Paracentesis: There are few contraindications while performing paracentesis. Coagulopathy should prevent paracentesis exclusively when there is clinically noticeable fibrinolysis or clinically obvious distributed intravascular coagulation. These situations occur in less than 1 per 1,000 procedures. There is no evidence-supported shut-off of coagulation parameters beyond which paracentesis should be prevented (Runyon, 1986).

\section{Use of Shunts}

In small number of patients suffering from advanced cirrhosis and have recurrent ascites, shunts may be used. Commonly used shunts are peritoneovenous shunt, portacaval shunt, and the transjugular intrahepatic portosystemic shunt (TIPS). Nevertheless, none of these shunts has been shown to extend life assurance, and are considered to be the link to liver transplantation. A metaanalysis of randomized controlled trials by the interna- 
tional Cochrane Collaboration agreed that "TIPS was more effective at removing ascites as compared with paracentesis, nonetheless, TIPS patients establish hepatic encephalopathy significantly more often" (Saab et al., 2006).

\section{Culturing bacteria for infection detection}

Bacterial culture should be performed if ascitic fluid infection is suspected i.e., fever, unexplained encephalopathy or abdominal pain. To identify neutropihils urine dipstick can also be used which hardly takes 90 seconds to minutes. Manual cell count can be replaced by automated cell counting in order to have more accurate and speedy results (Castellote et al., 2003; Eisenmenger et al., 1950).

It has been concluded from multiple prospective trials that when the polymorphonuclear leukocyte (PMN) count was more than or equal to 250 cells $/ \mathrm{mm} 3$ in the ascetic fluid was cultured by previous method, then the bacterial growth occurs in almost $50 \%$ of the cases in comparison to the ascitic fluid being inoculated into blood culture bottles at the patient's bedside was $80 \%$ (Angeloni et al., 2003).

\section{Usefulness of Baclofen}

Baclofen has been shown in a randomized trial, which included only patients with alcoholic liver disease, to decrease alcohol craving and alcohol consumption; it can be given at a dose of $5 \mathrm{mg}$ orally tid for 3 days and then 10 $\mathrm{mg}$ tid. Ascites in decompensated hepatitis B cirrhosis and autoimmune hepatitis can also have a dramatic response to specific treatment. Liver diseases other than alcoholrelated, hepatitis $\mathrm{B}$ and autoimmune hepatitis are less reversible; by the time ascites is present, these patients may be perfect served by referring for liver transplantation opinion rather than protracted medical treatment (Bruce et al., 2009; Addolorato et al., 2007).

\section{Use of vaptans}

Vaptans are a relatively new class of drugs (the vasopressin receptor antagonists) and have been studied predominantly in heart failure but also in the setting of cirrhosis. The most recent oral agent, satavaptan, was especially studied to find its efficacy in treating ascites rather than hyponatremia and was found to be "not clinically useful in the long-term treatment of ascites in cirrhosis" in a study including 1200 patients having cirrhosis. Satavaptan was also associated with higher mortality in comparison to placebo. These drugs can raise thirst (Sterns, 1987; Wong et al., 2003).

\section{Bed rest}

Unfortunately, many drugs that have theoretical promise in managing ascites, e.g., angiotensin-converting enzyme inhibitors, have been shown to exacerbate hypotension and have not been clinically helpful. Severe hyponatremia does ensure fluid restriction in the patient with cirrhosis and ascites; nonetheless, there is no evidence-supported specific threshold for initiating fluid restriction and no data-supported level of restriction. Although it is traditional to recommend bed rest (based on extrapolation from heart failure), this is illogical and there are no controlled trials to support this practice. Upright posture may worsen the plasma renin elevation found in patients with cirrhosis and ascites. Theoretically, this may increase sodium cupidity. This theoretical interest would have to translate into clinically relevant outcomes before bed rest could be advised (Schrier et al., 2006).

\section{COMPLICATIONS}

However, some patients with cirrhosis and ascites also have hepatic encephalopathy, gastrointestinal hemorrhage, bacterial infection, hypotension, azotemia, and/or hepatocellular carcinoma, and may need hospitalization for determinate diagnosis and management of their liver disease as well as management of their fluid overload. Diuretics should be retained in the setting of active gastrointestinal bleeding, hepatic encephalopathy or renal dysfunction. Frequently, intensive education is required to ensure patient understanding that the diet and diuretics are actually effective and worth the effort. There is no limit to the daily weight loss of patients who have significant edema. Once the edema has resolved, $0.5 \mathrm{~kg}$ is probably a sensible daily maximum. In the past, patients with ascites frequently occupied hospital beds for prolonged periods of time because of confusion regarding diagnosis and treatment and because of iatrogenic problems (Angeloni et al., 2003).

As, the ultimate aim is to have no clinically identifiable fluid in the abdomen; but it is not significant for getting discharge from the hospital. Patients, who are now stable, with ascites as their main problem, can be released from the clinic after it has been found that they are responding to their medical regimen. Liver transplantation should be considered in the treatment options of patients with ascites. Once patients become fractious to routine medical therapy, 50\% die within 6 months and $75 \%$ die within 1 year. Referral should not be delayed in patients with refractory ascites (Angeloni et al., 2003).

In patients with ascites possible associated complications are spontaneous bacterial peritonitis (a lifethreatening infection of the ascites fluid), hepatorenal syndrome (kidney failure), weight loss and protein malnutrition, mental confusion, coma (hepatic encephalopathy) or change in the level of alertness, and other complications related to liver cirrhosis (Mehta and Rothstein, 2009). Table 5 highlights some of the complications of ascites.

The most frequent decompensating event is the development of ascites in cirrhosis. Splanchnic and peripheral vasodilatation is the most common etiological factors causing ascites and leading to a decrease in effective volume of blood. When talk about the usual development of ascites, it is firstly a compensated event, in which patient responds to diuretics, then becoming resistant to its use, developing hyponatremia and finally leading to hepatorenal syndrome. Most patients respond to diuretics. Patients who no longer react should be managed with repeated large - volume paracenteses. Transjugular intrahepatic portosystemic shunt (TIPS) should be considered in those requiring frequent paracenteses. Fluid restriction is suggested in patients with hyponatraemia. Vasoconstrictors may revert hepatorenal syndrome and are useful as a bridge to liver transplantation. Ascites itself is not lethal unless it gets infected (spontaneous bacterial peritonitis). Infection often increases the hepatorenal syndrome leading to mortality. Antibiotic preventability is indicated for secondary prophylaxis of spontaneous bacterial peritonitis and in high - risk patients (Garcia-Tsao, 2011).

\section{CONCLUSION AND RECOMMENDATIONS}

Ascites is a lethal disease, which is common all over the world. Its early detection is required to ensure effective management without any complications. It may be due to hepatic or extra-hepatic causes. Treatment depends upon the cause of the ascites. Dietary sodium restriction and 
diuretics remains the first line therapy for its management. Ascites itself is not fatal, unless it becomes infected. So, awareness regarding this disease should be provided to the people.

\section{Recommendations:}

$>$ Dietary salt should be restricted to a no-added salt diet of $90 \mathrm{mmol}$ salt/day (5.2 g salt/day)

$>$ Proper prognosis should be made before starting the treatment, in order to get optimal therapeutic outcome.

$>$ In renal compromised patients, before performing dialysis certain hygienic parameters should be kept in mind by the patients like to wash hands (including fingernails), before touching the catheter. Cleaning the skin around the catheter daily. Following doctor's instructions regarding the care and storage of medical supplies.

$>$ Treatment must begin promptly after diagnosis in order to avoid serious and potentially fatal complications.

$>$ Laboratory examinations should be performed on periodic basis to check the disease progression and therapeutic effectiveness.

$>$ Due to compromised liver function unnecessary medications should be avoided

$>$ Therapeutic drug monitoring (TDM) should be performed for the drugs having narrow margin of safety

$>$ Pharmacist should counsel the patients regarding the potential side effects of the therapy, proper use and duration of therapy for the optimal outcome.

$>$ Pharmacist should counter check the prescription before handling to the patient.

$>$ Pharmacist should actively participate in patient awareness programs regarding Ascites.

\section{ACKNOWLEDGEMENT}

We would like to show our sincere regards to Prof. Dr. Maqsood Ahmad, Director of Institute of Pharmacy, Lahore College For Women University, Lahore, and all the supervisors who helped us. Even our thanks would not be enough for their tremendous support and help, without their encouragement and guidance this review would not have been possible. Last but not least we wish to avail ourselves of this opportunity to express a sense of gratitude and love to our beloved parents and lovely friends for their manual support, strength and help.

\section{REFERENCES}

Abbasoglu, O., Goldstein, R.M., Vodapally, M.S., Jennings, L.W., Levy, M.F., Husberg, B.S. and Klintmalm, G.B (1998). Liver transplantation in hyponatremic patients with emphasis on central pontine myelinolysis. Clinical Transplantation, Volume 12, Pages 263-269. PMid:9642521

Addolorato, G., Leggio, L., Ferrulli, A., Cardone, S., Vonghia, L., Mirijello, A., Abenavoli, L., D'Angelo, C., Caputo, F., Zambon, A., Haber, P.S. and Gasbarrini, G (2007) Effectiveness and safety of baclofen for maintenance of alcohol abstinence in alcohol-dependent patients with liver cirrhosis: randomized, double-blind controlled study. Lancet, Volume 370, Pages 1915-1922. [DOI]

Al Knawy, B.A (1997). Etiology of Ascites and the diagnostic value of serum-ascites albumin gradient in non-alcohol liver disease. Annals of Saudi Medicine, Volume 17, Issue 1, Pages 26-28.

Angeloni, S., Nicolini, G,, Merli, M., Nicolao, F., Pinto, G., Aronne, T., Attili A.F. and Riggio, O (2003) Validation of automated blood cell counter for the determination of polymorphonuclear cell count in the ascitic fluid of cirrhotic patients with or without spontaneous bacterial peritonitis. The American Journal of Gastroenterology, Volume 98, Pages 1844-1848. [DOI] PMid:12907342
Becker, G., Galandi, D. and Blum, H.E (2006) Malignant ascites: systematic review and guideline for treatment. European Journal of Cancer, Volume 42, Pages 589-597. [DOI] PMid:16434188

Castellote, J., Lopez, C., Gornals, J., Tremosa, G., Farina, E.R., Baliellas, C., Domingo, A. and Xiol X (2003) Rapid diagnosis of spontaneous bacterial peritonitis by use of reagent strips. Hepatology, Volume 37, Pages 893-896. [DOI] PMid:12668983

Cattau, E.L. Jr., Benjamin, S.B., Knuff, T.E. and Castell, D.O (1982) The accuracy of the physical exam in the diagnosis of suspected ascites. Journal of the American Medical Association, Volume 247, Pages 11641166. [DOI]

Eisenmenger, W.J., Ahrens, E.H., Blondheim, S.H. and Kunkel, H.G (1949) The effect of rigid sodium restriction in patients with cirrhosis of the liver and ascites. Journal of Laboratory and Clinical Medicine, Volume 34, Pages 1029-1038. PMid:18136205

Eisenmenger, W.J., Blondheim, S.H., Bongiovanni, A.M. and Kunkel, H.G (1950). Electrolyte studies on patients with cirrhosis of the liver. Journal of Clinical Investigation, Volume 29, Pages 1491-1499. [DOI] PMid:14794777 PMCid:PMC436197

Fogel, M.R., Sawhney, V.K., Neal, E.A., Miller, R.G., Knauer, C.M. and Gregory, P.B (1981). Diuresis in the ascetic patient: a randomized controlled trial of three regimens. Journal of Clinical Gastroenterology, Volume 3, Suppl 1, Pages 73-80. [DOI] PMid:7035545

Fullwood, D. and Purushothaman, A (2014). Managing ascites in patients with chronic liver disease. Nursing Standard, Volume 28, Issue 23, Pages 51-58. [DOI] PMid:24494916

Garcia-Tsao. G (2011). Ascites., Yale University School of Medicine, New Haven, and VA - CT Healthcare System, West Haven, CT, USA., Sherlock's Diseases of the Liver and Biliary System. Edited by Dooleym. J.S., Lok, A.S.F., Burroughs, A.K. and Jenny, E. Heathcote (12th ed., p.p 210-233). Blackwell Publishing Ltd.

Garg, H., Sarin, S.K., Kumar, M., Garg, V., Sharma, B.C. and Kumar, A (2011). Tenofovir improves the outcome in patients with spontaneous reactivation of hepatitis $B$ presenting as acute-on-chronic liver failure. Hepatology, Volume 53, Pages 774-780. [DOI] PMid:21294143

Gatta, A., Angeli, P., Caregaro, L., Menon, F., Sacerdoti, D and Merkel, C (1991). A pathophysiological interpretation of unresponsiveness to spironolactone in a stepped-care approach to the diuretic treatment of ascites in nonazotemic cirrhotic patients. Hepatology Volume 14, Issue 2, Pages 231-236. [DOI] PMid:1860680

Ginès, P., Arroyo, V., Quintero, E., Planas, R., Bory, F., Cabrera, J., Rimola, A., Viver, J., Camps, J., Jiminéz, W., Mastai, R., Gaya, J and Rodés, J (1987). Comparison of paracentesis and diuretics in the treatment of cirrhotics with tense ascites. Results of a randomized study. Gastroenterology, Volume 93, Issue 2, Pages 234-241. [DOI]

Ginès, P., Cárdenas, A., Arroyo, V. and Rodés, J (2004). "Management of cirrhosis and ascites". The New England Journal of Medicine, Volume 350, Issue 16, Pages 1646-54. [DOI] PMid:15084697

Ginés, P., Quintero, E., Arroyo, V., Terés, J., Bruguera, M., Rimola, A., Caballería, J., Rodés, J. and Rozman, C (1987). Compensated cirrhosis: natural history and prognostic factors. Hepatology, Volume 7, Pages 122 - 128. [DOI] PMid:3804191

Henriksen, J.H. and Møller, S (2005). Alterations of hepatic and splanchnic microvascular exchange in cirrhosis: local factors in the formation of ascites. In: Ginès, P., Arroyo, V., Rodés, J., Schrier, R.W., editors. Ascites and renal dysfunction in liver disease. Malden: Blackwell, Pages 174185. [DOI]

Hunt, S.A., Abraham, W.T., Chin, M.H., Feldman, A.M., Francis, G.S., Ganiats, T.G., et al (2005) "ACC/AHA 2005 Guideline Update for the Diagnosis and Management of Chronic Heart Failure in the Adult: a report of the American College of Cardiology/American Heart Association Task Force on Practice Guidelines". Circulation 112, Issue 12, Pages 154-235. [DOI]

Llach, J., Ginès, P., Arroyo, V., Rimola, A., Titó, L., Badalamenti, S., Jiménez, W., Gaya, J., Rivera, F. and Rodés, J (1988). Prognostic value of arterial pressure, endogenous vasoactive systems, and renal function in cirrhotic patients admitted to the hospital for the treatment of ascites. Gastroenterology, Volume 94, Pages 482-487. PMid:3335320

Marthadu (2014). Evaluation of New Onset Ascites in a Patient with Chronic Hepatitis C. Hepatitis Web Study. [Assessed: November, 2014]. Available from: [Link]

Mehta, G. and Rothstein, K.D (2009). Health maintenance issues in cirrhosis. Medical Clinics of North America, Volume 93, Pages 901-915. [DOI]

Moore, C.M. and Thiel, D.H (2013). Cirrhotic ascites review: Pathophysiology, diagnosis and management. World Journal of Hepatology, Volume 5, Issue 5, Pages 251-263. [DOI 
Moore, K.P and Wong, F (2003). The management of ascites in cirrhosis: report on the consensus conference of the International Ascites Club. Hepatology, Volume 38, Pages 258-66. [DOI]

Muhammed, H., Aslam, Saleem, S., Alvi, A.A. and Hasan, S.S (2012). Epidemiology and Symptomatology of Exudative and Transudative type of Ascites in Hospitalized Patients. Pakistan Journal of Pharmacology, Volume 29, Issue 2, Pages 1-6.

Pinzello, G., Simonetti, R.G., Craxi, A., di, Piazza. S., Spano, C. and Pagliaro, L (1983). Spontaneous bacterial peritonitis: a prospective investigation in predominantly nonalcoholic patients. HEPATOLOGY Volume 3, Pages 545-549. PMid:6862365

Planas, R., Balleste, B., Alvarez, M.A., Rivera, M., Montoliu, S., Galeras, J.A., Santos, J., Coll, S., Morillas, R.M. and Sola, R (2004). Natural history of decompensated hepatitis $C$ virus-related cirrhosis. A study of 200 patients. J Hepatol, Volume 40, Pages 823-830. [DOI] PMid:15094231

Runyon, B.A (2009). Management of Adult Patients with Ascites. AASLD PRACTICE GUIDELINE Due to Cirrhosis: Update 2012., Revised and updated guideline based on the previously published version. Hepatology, Volume 49, Pages 2087-107. [DOI] PMid:19475696

Runyon, B.A (1993) Ascites, In: Schiff L, Schiff ER, eds. Diseases of the Liver (Volume 2, pp. 990 - 1015). Philadelphia: Lippincott Company. [DOI]

Runyon, B.A (2002). Ascites and spontaneous bacterial peritonitis. In: Feldman, M., Friedman, L.S., Sleisenger, M.H., eds. Sleisenger and Fordtran's Gastrointestinal and Liver Disease (7th ed., p.p 1517-1542). Philadelphia: Saunders.

Runyon, B.A (1994). Care of patients with ascites. The New England Journal of Medicine, Volume 330, Pages 337-342. [DOI] PMid:8277955

Runyon, B.A (1986). Paracentesis of ascitic fluid: a safe procedure. Archives of Internal Medicine, Volume 146, Pages 2259-2261. [DOI] PMid:2946271

Runyon, B.A., Montano, A.A., Akriviadis, E.A., Antillon, M.R., Irving, M.A and McHutchison, J.G (1992). The serum-ascites albumin gradient is superior to the exudate-transudate concept in the differential diagnosis of ascites. Annals of Internal Medicine, Volume 117, Pages 215-220. [DOI] PMid:1616215
Saab, S., Nieto, J.M., Lewis, S.K. and Runyon, B.A (2006). "TIPS versus paracentesis for cirrhotic patients with refractory ascites". Cochrane database of systematic reviews (Online) (4): CD004889. [DOI] PMID 1705422

Sakai, H., Mendler, M.H. and Runyon, B.A (2002). The left lower quadrant is the best site for paracentesis: an ultrasound evaluation [abstract]. HEPATOLOGY, Volume 36, Page 525A.

Salerno, F., Badalamenti, S., Incerti, P., Tempini, S., Restelli, B., Bruno, S., Bellati, G. and Roffi, L (1987). Repeated paracentesis and i.v. albumin infusion to treat 'tense' ascites in cirrhotic patients. A safe alternative therapy. Journal of Hepatology, Volume 5, Issue 1, Pages 102-108. [DOI]

Schrier, R.W., Gross, P., Gheorghiade, M., Berl, T., Verbalis, J.G., Czerwiec F.S. and Orlandi, C (2006). Tolvaptan, a selective oral vasopressin V2receptor antagonist, for hyponatremia. The New England Journal of Medicine, Volume 355, Pages 2099-2112. [DOI] PMid:17105757

Simel, D.L., Halvorsen, R.A. Jr. and Feussner, J.R (1988). Quantitating bedside diagnosis: clinical evaluation of ascites. Jounal of General Internal Medicine, Volume 3, Pages 423 - 428. [DOI]

Sterns, R.H (1987). Severe hyponatremia: treatment and outcome. Annals of Internal Medicine, Volume 107, Pages 656-664. [DOI] PMid:3662278

Teirstein, A.S., Judson, M.A., Baughman, R.P., Rossman, M.D., Yeager, H. and Moller, D.R (2005). The spectrum of biopsy sites for the diagnosis of sarcoidosis. Sarcoidosis Vasc Diffuse Lung Dis, Volume 22, Pages 139-146. PMid:16053030

Warrell, D.A., Cox, T.N., Firth, J.D. and Benz, E.D (2003). Oxford textbook of medicine. Oxford: Oxford University Press. PMCid:PMC1125324

Webster, S.T., Brown, K.L, Lucey, M.R. and Nostrant, T.T (1996). Hemorrhagic complications of large volume abdominal paracentesis. The American Journal of Gastroenterology, Volume 92, Pages 366-368.

Wong, F., Blei, A.T., Blendis, L.M. and Thulavath, P.J (2003). A vasopressin receptor antagonist (VPA-985) improves serum sodium concentration in patients with hyponatremia: a multicenter, randomized, placebocontrolled trial. Hepatology, Volume 37, Pages 182-191. [DOI] PMid:12500203

Wong, F., Watson, H., Gerbes, A., Vilstrup, H., Badalamenti, S., Bernardi, M. and Gines, P (2012). Satavaptan for the management of ascites in cirrhosis: efficacy and safety across the spectrum of ascites severity. Gut, Volume 61, Pages 108-116. [DOI] PMid:21836029 